\title{
The prevalence of osteoarthritis of the intact hip and knee among traumatic leg amputees
}

Citation for published version (APA):

Struyf, PA., van Heugten, C. M., Hitters, M. W., \& Smeets, R. J. E. M. (2009). The prevalence of osteoarthritis of the intact hip and knee among traumatic leg amputees. Archives of Physical Medicine and Rehabilitation, 90(3), 440-446. https://doi.org/10.1016/j.apmr.2008.08.220

Document status and date:

Published: 01/01/2009

DOI:

10.1016/j.apmr.2008.08.220

Document Version:

Publisher's PDF, also known as Version of record

Document license:

Taverne

Please check the document version of this publication:

- A submitted manuscript is the version of the article upon submission and before peer-review. There can be important differences between the submitted version and the official published version of record.

People interested in the research are advised to contact the author for the final version of the publication, or visit the DOI to the publisher's website.

- The final author version and the galley proof are versions of the publication after peer review.

- The final published version features the final layout of the paper including the volume, issue and page numbers.

Link to publication

\footnotetext{
General rights rights.

- You may freely distribute the URL identifying the publication in the public portal. please follow below link for the End User Agreement:

www.umlib.nl/taverne-license

Take down policy

If you believe that this document breaches copyright please contact us at:

repository@maastrichtuniversity.nl

providing details and we will investigate your claim.
}

Copyright and moral rights for the publications made accessible in the public portal are retained by the authors and/or other copyright owners and it is a condition of accessing publications that users recognise and abide by the legal requirements associated with these

- Users may download and print one copy of any publication from the public portal for the purpose of private study or research.

- You may not further distribute the material or use it for any profit-making activity or commercial gain

If the publication is distributed under the terms of Article $25 \mathrm{fa}$ of the Dutch Copyright Act, indicated by the "Taverne" license above, 


\title{
The Prevalence of Osteoarthritis of the Intact Hip and Knee Among Traumatic Leg Amputees
}

\author{
Pieter A. Struyf, MD, Caroline M. van Heugten, PhD, Minou W. Hitters, MD, Rob J. Smeets, MD, PhD
}

ABSTRACT. Struyf PA, van Heugten CM, Hitters MW, Smeets RJ. The prevalence of osteoarthritis of the intact hip and knee among traumatic leg amputees. Arch Phys Med Rehabil 2009;90:440-6.

Objective: To determine the prevalence of osteoarthritis (OA) in the knee and/or hip of the intact leg among traumatic leg amputees compared with the general population and its relationship with amputation level, time since amputation, age, and mobility.

Design: Cross-sectional observational study.

Setting: Outpatient population of 2 Dutch rehabilitation centers.

Participants: Patients $(\mathrm{N}=78)$ with a unilateral traumatic transtibial amputation, knee disarticulation, or transfemoral amputation of at least 5 years ago; ability to walk with a prosthesis; older than 18 years of age; and able to understand Dutch. Patients were excluded if they had bilateral amputations, other pathologies of the knee or hip, or central neurologic pathologies.

Interventions: Not applicable.

Main Outcome Measure: The prevalence of OA.

Results: The prevalence of knee OA was $27 \%$ (men $28.3 \%$, women $22.2 \%$ ) and hip OA was $14 \%$ (men $15.3 \%$, women $11.1 \%)$. This was higher compared with the general population (knee OA men $1.58 \%$, women $1.33 \%$, hip OA men $1.13 \%$, women $0.98 \%$, age adjusted). No significant relationships between the prevalence of OA and level of amputation, time since amputation, mobility, and age were found.

Conclusions: The prevalence of OA is significantly greater for both the knee and hip in the traumatic leg amputee population. No specific risk factors were identified. Although no specific risk factors in this specific population could be identified, it might be relevant to apply commonly known strategies to prevent OA as soon as possible after the amputation.

Key Words: Amputation; Lower extremity; Osteoarthritis; Rehabilitation.

(C) 2009 by the American Congress of Rehabilitation Medicine

N MEDICAL PRACTICE, patients with a traumatic amputation often complain of pain and loss of mobility in the intact leg. A plausible explanation could be that these patients

From the Rehabilitation Centre Blixembosch, Eindhoven (Struyf, van Heugten, Hitters, Smeets); Maasland Hospital, Sittard (Struyf); Maastricht University, Maastricht (van Heugten, Smeets); Centre of Excellence in Rehabilitation Medicine, Rudolf Magnus Institute, Utrecht (van Heugten); Rehabilitation Foundation, Limburg (Smeets), The Netherlands.

No commercial party having a direct financial interest in the results of the research supporting this article has or will confer a benefit on the authors or on any organization with which the authors are associated.

Reprint requests to Pieter A. Struyf, MD, Dept of Rehabilitation Medicine, Maasland Hospital, PO Box 5500, 6130 MB Sittard, The Netherlands, e-mail: pieter.struyf@telenet.be.

0003-9993/09/9003-00531\$36.00/0

doi:10.1016/j.apmr.2008.08.220 develop $\mathrm{OA}$ at a faster rate than nonamputees. Changes in gait pattern with alterations of ground reaction forces in the intact limb have been documented. ${ }^{1}$ In the current literature, some evidence is found for the hypothesis that gait alteration and increased joint load exhibited by amputees with a prosthesis may result in abnormal joint loading that, over time, may lead to joint pain and degeneration. . $^{2,3}$

OA was once thought to occur as a result of aging, when the joints were just worn out.

Although the etiology of OA remains elusive, the imbalance between the synthesis and degradation of the articular cartilage results in increased deterioration or breakdown of the cartilage and the formation of new bone at the joint surfaces and margins. This breakdown of joint cartilage often results in joint pain and loss of mobility, which may lead to long-term disability. OA occurs when the cartilage is loaded in a different way and the cartilage is not able to adjust itself to this altered demand. OA has a multifactorial origin that can be divided into local biomechanical and systemic factors.

Systemic risk factors for OA include age and sex. ${ }^{4}$ Evidence is also found for the importance of nutritional factors, estrogen status, bone density, and genetic factors. ${ }^{4,5}$ In a recent review, Spector and MacGregor ${ }^{6}$ suggested the importance of the genetic component; a heritability of $50 \%$ or more for OA of hand and hip was found, with a lower percentage for the knee. Local biomechanical factors are obesity, joint deformity, malalignment, trauma (intra-articular fractures), meniscus pathology, ligament injury, muscular weakness, ligament laxity, proprioceptive problems, overloading by risk sports, and occupations. ${ }^{5}$ Sports with high intensity and acute direct impact on the joints, repetitive stress, and torsion on joints are associated with degenerative changes. ${ }^{7,8}$ The same applies to occupations requiring kneeling or squatting along with heavy lifting. ${ }^{9}$

In the current literature, some evidence is found that traumatic leg amputees are at a greater risk than nonamputees of developing OA in the knee or hip of the intact limb. Norvell et $\mathrm{al}^{3}$ conducted a retrospective cohort study including 62 male American war veterans with a traumatic transtibial or transfemoral amputation. They found an overall prevalence of symptomatic knee OA of $16.1 \%$ and $11.7 \%$ for amputees and nonamputees, respectively. The standardized prevalence ratio of symptomatic OA for the knee of the intact limb was 1.4 among transtibial amputees and 1.3 among transfemoral amputees. ${ }^{3}$ The diagnosis of OA of the knee by using the ACR criteria was established by a telephone interview. OA of the hip was not investigated. The mean age of the amputees was 63 years. Transfemoral amputations were present in $29 \%$, and $71 \%$ had transtibial amputations. Time since amputation was not mentioned.

List of Abbreviations

$\begin{array}{ll}\text { ACR } & \text { American College of Rheumatology } \\ \text { BMI } & \text { body mass index } \\ \text { OA } & \text { osteoarthritis } \\ \text { SIGAM } & \text { Special Interest Group on Amputee Medicine }\end{array}$


Another retrospective cohort study including 44 male British war veterans showed a prevalence of OA of the hip of the intact limb of $23 \%$. The diagnosis of hip OA was determined from a single anterior-posterior pelvic radiograph using minimum joint space and the Kellgren and Lawrence scoring system. ${ }^{2} \mathrm{OA}$ of the knee was not investigated. The mean age of the amputees was 73 years. Transfemoral amputations were present in 34\%, and $29 \%$ had transtibial amputations. Time since amputation was not mentioned.

Finally, a study consisting of 32 male amputees ( 8 volleyball players, 24 nonvolleyball players) reported a prevalence of $65.6 \% \mathrm{OA}$ of the knee of the intact limb. ${ }^{10}$ The presence of knee OA was determined by a questionnaire, physical examination, and radiographs.

As the most common form of arthritis, OA accounts for high costs and great dependency in the affected population. ${ }^{11}$ Therefore, it is of great importance to identify as early as possible those patients who are at risk of developing OA. Effective chondroprotective therapy could be useful when applied to high-risk individuals before the emergence of symptoms. ${ }^{12}$ Especially in the amputee, the intact leg is most essential for the preservation of mobility. Possible preventive measures are weight reduction, prevention of knee trauma, adjusted work, and sports participation. ${ }^{13}$ For example, weight loss can reduce the risk for knee OA by $50 \% .{ }^{14}$ Eliminating jobs requiring knee bending and carrying would decrease OA rates by $15 \%$ to $30 \% .^{13}$

Therefore, the main objective of this study was to determine the prevalence of OA in knee and/or hip of the intact leg among traumatic amputees in a common rehabilitation population. The second objective was to determine a relation between the presence of OA and factors that can be influenced in health care on the one hand (eg, weight, mobility, work, and sports) and amputation level, time since amputation, and age on the other hand.

\section{METHODS}

\section{Design}

A cross-sectional observational study was conducted. Patients were examined once with a physical examination, they had to fill out a questionnaire, and the medical record was checked.

\section{Participants}

All unilateral traumatic amputation patients $(n=237)$ of the outpatient population of 2 Dutch rehabilitation centers (Eindhoven, Tilburg) were identified. After checking the databases of the prosthetic companies affiliated with the rehabilitation centers, 192 patients appeared to be possible candidates for the study (ie, alive and known address). Inclusion criteria were traumatic transtibial amputation, knee disarticulation, and transfemoral amputation of at least 5 years before start of the study; able to walk with a prosthesis; older than 18 years of age; and able to read and fill out a questionnaire. Exclusion criteria were bilateral amputations, central neurologic comorbidity, inflammatory joint diseases, and/or fractures of articular surfaces in the nonamputated hip or knee and not giving permission to participate. We selected traumatic amputees because of their higher life expectancy resulting in a higher chance of developing $\mathrm{OA}$ and minimalizing interference of vascular pathology. Traumatic amputees are also better ambu-

A

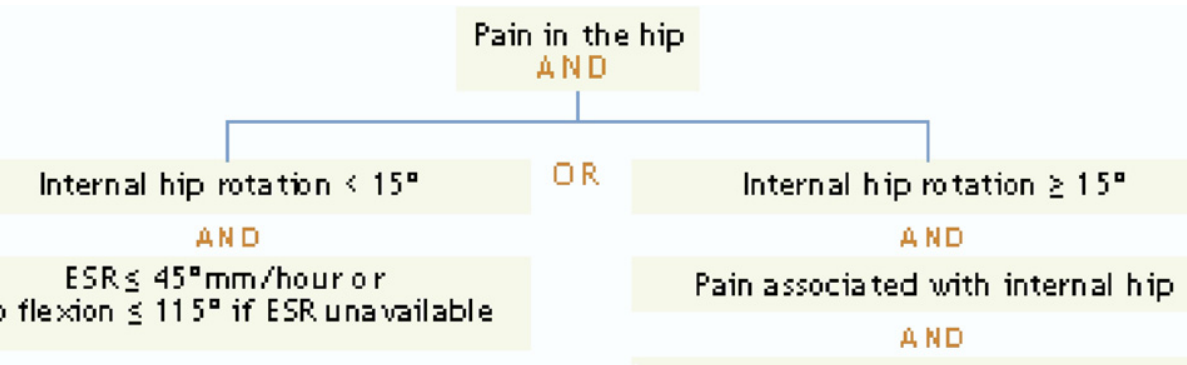

whorning stiffness of the hip $\leq 60$ minutes

Duer 50 years of age

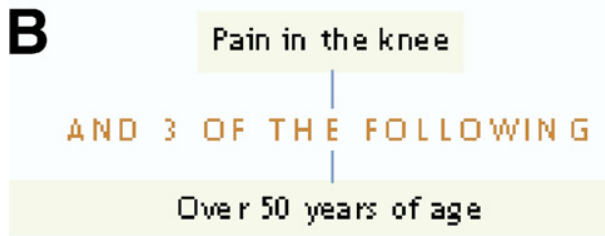

Fig 1. ACR classification criteria for $\mathrm{OA}$ of hip and knee. (A) ACR-clinical classification criteria for osteoarthritis of the hip (1991) using history, physical examination, and laboratory data. (B) ACR-clinical classification criteria for osteoarthritis of the knee (1986) using history and physical examination. Abbreviation: ESR erythrocyte sedimentation rate.

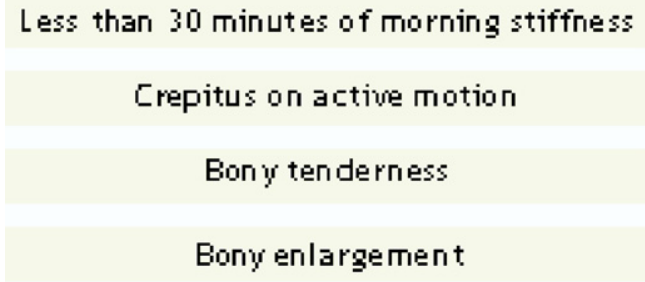

No palpable warmth of synovium 
lators and participate more in sports and work than vascular amputees, which provides more possibilities to check for found risk factors that can be addressed by the implementation of preventive measures.

\section{Procedure}

Patients were recruited through the database of the prosthetic companies in Eindhoven and Tilburg because they appeared to be more complete than the databases of the rehabilitation centers. The prosthetic company contacted the patients who met the inclusion criteria for the study by telephone informing them about the purpose of the study and asking whether they were interested in participating. The companies were not involved in any other way. If a patient considered participation, the main researcher (PS) contacted them by telephone, checked the exclusion criteria, sent an informed consent form, and made an appointment to visit the participant for data collection. One visit was made in which the consent form was checked, the physical examination was conducted, and the questionnaire was filled out by the patient. The patient was also asked to give permission to check his/her medical records at the rehabilitation center. This procedure was approved by the local medical ethics committee of the Rehabilitation Foundation, Limburg and the Institute for Rehabilitation Research in Hoensbroek, The Netherlands.

\section{Measurements}

The physical examination was conducted by 2 rehabilitation physicians (PS, MH) to assess the presence of osteoarthritis in the hip and/or knee of the intact leg. To establish the presence of OA, the criteria of the ACR were used ${ }^{15}$ (fig 1). The classification method for the hip has a sensitivity of $86 \%$ and a specificity of $75 \%{ }^{16}$; the classification of the knee has a sensitivity of $95 \%$ and specificity of $69 \% .{ }^{17}$ Joint mobility of the hip was measured with a gravity goniometer. ${ }^{18, a}$

The questionnaire consisted of questions necessary for the diagnosis of OA, risk factors for OA, and questions related to the amputation and the SIGAM mobility scale. Risk factors for OA including age, sex, obesity, estrogen status, family history of $\mathrm{OA}$, the presence of osteoporosis, risk occupations, and sports were assessed to identify possible confounders. The SIGAM mobility scale was translated into Dutch and validated in Dutch by Rommers. ${ }^{19}$ The inter- and intraobserver reliability and responsiveness have been proven to be good. This questionnaire consists of 21 questions filled out by the patient. Using a mobility scale is preferred over a walking test because these tests are performed under standardized conditions that do not correspond with the reality of daily life. ${ }^{20}$

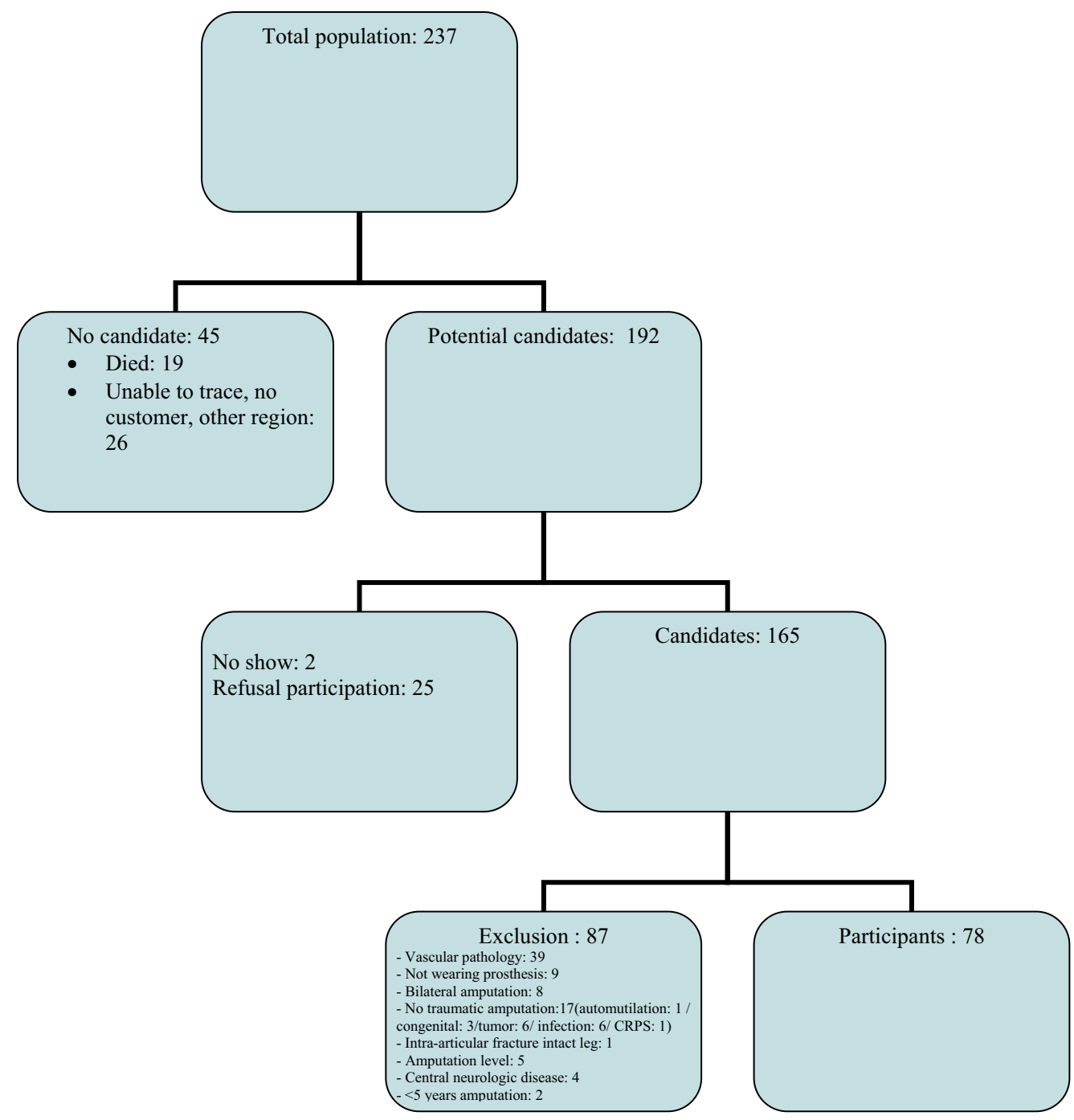

Fig 2. Patient flow. Abbreviation: CRPS, complex regional pain syndrome. 


\section{Data Analysis}

Descriptive statistics were used to characterize the population. The weight of the patients was corrected for the loss of body weight because of the amputation. For transtibial amputations, a correction of $4.5 \%$ was used; for knee exarticulations, a correction of $7.1 \%$ was used; and for transfemoral amputations, a correction of $12.9 \%$ was used. ${ }^{21}$ For comparison of prevalence rates in the Dutch general population, prevalence rates standardized for age and sex were used. ${ }^{22}$ To determine the prevalence of $\mathrm{OA}$ in the general population, the general practitioners' registrations of 5 registration studies in The Netherlands were used: CMR-Nijmegen e.o. (1996-2000), Tweede Nationale Studie (2000-2002), RNH-Limburg (19972000), RNUH-LEO (1998-2001), and Transitieproject (19852000). ${ }^{22}$

Chi-square and independent $t$ tests were used to test differences between patients with and without OA for the following variables: sex, age, weight, family history of OA, time since

Table 1: Patient Characteristics

\begin{tabular}{|c|c|c|c|c|}
\hline Characteristics & $\mathrm{n}$ & $\%$ & Range & Median (IQR) \\
\hline \multicolumn{5}{|l|}{ Sex } \\
\hline Male & 60 & 77 & & \\
\hline Female & 18 & 23 & & \\
\hline Age $(y)$ & \multicolumn{2}{|c|}{$54.5 \pm 13.1$} & $20-85$ & $53.0(46.7-63.0)$ \\
\hline Weight $(\mathrm{kg})$ & \multicolumn{2}{|c|}{$80.8 \pm 11.2$} & $60-130$ & $80.0(73.8-88.1)$ \\
\hline Weight adjusted $(\mathrm{kg})$ & \multicolumn{2}{|c|}{$86.6 \pm 12.2$} & $63-139$ & $87.0(77.5-94.0)$ \\
\hline Length $(\mathrm{cm})(\mathrm{n}=77)$ & \multicolumn{2}{|c|}{$174 \pm 7.3$} & 154-193 & $173(170-180)$ \\
\hline BMI $(n=77)$ & \multicolumn{2}{|c|}{$28.5 \pm 3.5$} & $22.0-38.9$ & $28.1(25.9-31.1)$ \\
\hline $\mathrm{BMI}>25$ & 66 & 86 & & \\
\hline \multicolumn{5}{|l|}{ Level of amputation } \\
\hline Transtibial & 43 & 55 & & \\
\hline Knee disarticulation & 11 & 14 & & \\
\hline Transfemoral & 24 & 31 & & \\
\hline \multicolumn{5}{|l|}{ Side of amputation } \\
\hline Right & 29 & 38 & & \\
\hline Left & 48 & 62 & & \\
\hline \multicolumn{5}{|l|}{ Pain in stump } \\
\hline Yes & 36 & 46 & & \\
\hline No & 42 & 54 & & \\
\hline Use of pain medication & 11 & 14 & & \\
\hline Phantom limb pain & 37 & 47 & & \\
\hline Time since amputation (y) & \multicolumn{2}{|c|}{$28.9 \pm 15.3$} & $5-62$ & $30.0(16.0-39.3)$ \\
\hline \multicolumn{5}{|l|}{ OA } \\
\hline Knee & 21 & 27 & & \\
\hline $\operatorname{Hip}(n=77)$ & 11 & 14 & & \\
\hline Knee and hip $(n=77)$ & 8 & 10.3 & & \\
\hline Family history of OA $(n=77)$ & 10 & 13 & & \\
\hline \multicolumn{5}{|l|}{ Pain in healthy limb } \\
\hline Knee & 32 & 41 & & \\
\hline Hip & 20 & 26 & & \\
\hline \multicolumn{5}{|l|}{ Use of walking aids } \\
\hline Yes & 26 & 33 & & \\
\hline No & 52 & 67 & & \\
\hline \multicolumn{5}{|l|}{ Mobility (SIGAM) } \\
\hline Grade A (abandoned/cosmetic) & 0 & 0 & & \\
\hline Grade B (transfers/nursing/therapy) & 0 & 0 & & \\
\hline Grade $C(<50 \mathrm{~m}$, even ground $)$ & 1 & 1 & & \\
\hline Grade $D(>50 m$, uneven ground) & 21 & 27 & & \\
\hline Grade E (occasional aid outside) & 10 & 13 & & \\
\hline Grade F (near normal/normal) & 46 & 59 & & \\
\hline \multicolumn{5}{|l|}{ Sports } \\
\hline Yes & 32 & 41 & & \\
\hline No & 46 & 59 & & \\
\hline Sports with risk of OA & 3 & 4 & & \\
\hline \multicolumn{5}{|l|}{ Work } \\
\hline Yes & 32 & 41 & & \\
\hline No & 46 & 59 & & \\
\hline Work with risk of OA & 14 & 18 & & \\
\hline Former work with risk of $\mathrm{OA}$ & 10 & 13 & & \\
\hline
\end{tabular}

Abbreviation: IQR, interquartile range.

*Values are mean \pm SD unless otherwise indicated 
Table 2: Prevalence of OA in Comparison to the General Population

\begin{tabular}{cccccc}
\hline & \multicolumn{2}{c}{ Traumatic Amputees } & & \multicolumn{2}{c}{ General Population* } \\
\cline { 2 - 3 } \cline { 6 - 6 } OA Type & Male (\%) & Female (\%) & & Male (\%) & Female (\%) \\
\hline Knee & 28.3 & 22.2 & & 1.58 & 1.33 \\
Hip & 15.3 & 11.1 & & 1.13 & 0.98 \\
\hline
\end{tabular}

* Year prevalence of OA in general practitioner registration standardized for age and sex in The Netherlands in $2000 .^{22}$

amputation, level of amputation, and mobility. Alpha was set at .01 ; this includes a Bonferroni correction for multiple comparisons. SPSS version $13^{\mathrm{b}}$ was used.

\section{RESULTS}

\section{Participants}

The population of potential candidates for the study consisted of 192 patients. A total of 78 traumatic amputees (43 transtibial, 11 knee disarticulations, and 24 transfemoral) met the study criteria and had complete data $(40.6 \%)$. The patient flow is shown in figure 2; the total population of 237 was reduced to 87 participants after applying the inclusion and exclusion criteria.

The characteristics of the patients are shown in table 1 . Three quarters were men; the mean age \pm SD was $54.5 \pm 13.1$ years. The mean BMI was $28.5 ; 86 \%$ were overweight (ie, BMI>25). Almost half of the patients reported pain in the stump. More than half of the patients had normative mobility patterns. One patient reported a history of osteoporosis, and 3 women used hormone substitutes altering estrogen status.

\section{Prevalence of Osteoarthritis}

The overall prevalence of knee OA was $21(27 \%)$ of 78 subjects, 11 (14\%) of 78 subjects for hip OA, and $8(10.3 \%)$ of 78 subjects for OA in both the knee and hip. One patient was younger than 50 years of age when $\mathrm{OA}$ of the knee was diagnosed. (One of the ACR criteria is age over 50 years of age.) Most patients had an amputation of the left leg (62\%), and the time since amputation was $28.9 \pm 15.3$ years on average.

In comparison with the prevalence of $\mathrm{OA}$ in the general population according to general practitioners' registration in The Netherlands (table 2), a higher prevalence of OA in both the knee and hip of the intact limb was found in the amputee population.

\section{Relationship With Other Factors}

In table 3, the presence of $\mathrm{OA}$ is shown in relation to putative risk variables. Participants with and without OA of the knee or hip did not differ significantly with respect to all variables tested including time since amputation, level of amputation, and mobility. The potential confounding factors sex, weight, and family history of OA also did not differ significantly between the groups with and without OA of the hip and knee. Because of the low prevalence of hormone substitution, osteoporosis, and work and sports with a high risk of developing OA, these relationships were not further investigated.

\section{DISCUSSION}

The main objective of this study was to determine the prevalence of OA in the knee and/or hip of the intact leg among traumatic leg amputees. The second objective was to determine whether there is a relation between the presence of OA and amputation level, time after amputation, age, and mobility.

The overall prevalence of knee OA was $27 \%$, hip OA was $14 \%$, and $\mathrm{OA}$ in both the knee and hip was $10.3 \%$. These results are largely comparable to the results in previous studies, despite their selective population characteristics (ie, male veterans and volleyball players ${ }^{2,3,10}$ ) and the way the diagnosis of OA was established (ie, by telephone interview ${ }^{3}$ ). In comparison to the general population, the group of amputees in our study had much higher prevalence rates. This could not be explained by age and sex because the rates for the general population were also age adjusted. In the present study, factors associated with the presence of OA were not found. The results

Table 3: Characteristics of Patients With and Without OA of Hip and Knee

\begin{tabular}{|c|c|c|c|c|c|c|}
\hline \multirow[b]{2}{*}{ Characteristics } & \multicolumn{3}{|c|}{ Hip OA } & \multicolumn{3}{|c|}{ Knee OA } \\
\hline & No & Yes & $P$ & No & Yes & $P$ \\
\hline $\operatorname{Age}^{*}$ & $53.8(13.3)$ & $59.3(11.9)$ & .20 & $52.4(13.2)$ & $60.2(11.1)$ & .01 \\
\hline Time since amputation* & $28.3(15.2)$ & $32.5(17.1)$ & .40 & $28.1(15.0)$ & $31.2(16.2)$ & .45 \\
\hline \multicolumn{7}{|l|}{ Level of amputation } \\
\hline Transtibial & 36 & 7 & .84 & 31 & 12 & .78 \\
\hline Knee disarticulation & 9 & 1 & & 9 & 2 & \\
\hline Transfemoral & 21 & 3 & & 17 & 7 & \\
\hline \multicolumn{7}{|l|}{ Mobility } \\
\hline Grade A-E & 26 & 5 & .70 & 20 & 12 & .08 \\
\hline Grade F & 40 & 6 & & 37 & 9 & \\
\hline \multicolumn{7}{|l|}{ Sex } \\
\hline Male & 50 & 9 & .66 & 43 & 17 & .61 \\
\hline Female & 16 & 2 & & 14 & 4 & \\
\hline Weight* & $79.4(9.7)$ & $84.5(8.9)$ & .10 & $80.8(11.7)$ & $80.8(9.9)$ & 1.00 \\
\hline \multicolumn{7}{|l|}{ Overweight } \\
\hline $\mathrm{BMI}>25$ & 56 & 9 & .67 & 49 & 17 & .92 \\
\hline $\mathrm{BMI} \leq 25$ & 10 & 1 & & 8 & 3 & \\
\hline \multicolumn{7}{|l|}{ Family history of OA } \\
\hline Yes & 9 & 1 & .67 & 6 & 4 & .33 \\
\hline No & 56 & 10 & & 50 & 17 & \\
\hline
\end{tabular}

* $t$ test was used for independent samples; for all other variables, the chi-square test was used. 
imply that traumatic leg amputees in general are at a relatively high risk for developing OA, but no specific risk factor such as amputation level, time after amputation, age, and general mobility could be identified.

If traumatic amputees are indeed high-risk individuals, they would benefit the most from commonly known primary preventive strategies as soon as possible immediately after the amputation. The currently known modifiable risk factors are obesity, occurrence of knee injury, and jobs requiring bending and carrying. ${ }^{13}$ Femoral muscle strengthening can also be an effective strategy for primary prevention. ${ }^{13}$ In other words, from the moment an amputee patient starts walking with a prosthesis, abnormal joint loadings can appear; these should be prevented as much as possible. In addition, in our group, a large amount of subjects was overweight, even when correcting for the loss of body mass because of the amputation. Weight control would be an evident strategy. From studies on the prevention of OA, we also know that avoiding work and sports with a high risk of developing OA and exercises that strengthen the femoral muscles to minimize joint loading should also be considered.

The impact of knee pain and symptomatic OA on the mobility of the amputee has not been investigated before. In a recent study on the mobility of amputees, Geertzen et $\mathrm{al}^{23}$ found that the chance of walking $500 \mathrm{~m}$ or more reduced with an increase in age, vascular disease, a more proximal amputation, phantom pain, and stump pain. In our study, we found no relationship between $\mathrm{OA}$ and mobility grade. However, it should be taken into account that the use of the SIGAM to measure mobility showed a ceiling effect because most amputees had normal or near to normative mobility (ie, the highest scoring level).

The quality of prosthetics for leg amputees has improved drastically over the past 10 years. This might lead to less abnormal joint loadings in the current population than was apparent in the population we studied because the time since amputation was rather long in our group (28.9y on average).

\section{Study Limitations}

There was a limitation in our study. Although 78 is a considerable number of traumatic amputees, to study the prevalence of OA of knee and hip in the nonamputated leg, a prospective design with a larger number of patients is needed to study relationships between risk factors and the presence of OA. Furthermore, this extremely common and often functionally disabling condition needs additional research as a major target area in physiatry, as already stated by Stitik and Foye. ${ }^{24}$

Prospective studies in the general population identified obesity and increased joint load as being risk factors for the development of OA. ${ }^{5,7-9}$ Our results do not refute the use of generally advised preventive measures such as weight control and proper reduction of weight load (eg, avoiding work and sports causing high loadings of the intact limb, optimizing the strength of femoral muscles). ${ }^{13}$

During the investigation, several participants mentioned spontaneously that they hop on 1 leg during transfer or short distances. For example, some participants hop to the toilet during the night to gain time by not putting on the prosthesis. Unfortunately, this heavy joint loading activity and the time the patient was using this form of ambulation was not taken into account at the start of our study.

Although ongoing clinical drug trials mostly use standardized plain radiographs to monitor structural changes in the joint, the good relationship between the preservation or improvement of joint structure and improvement in patient-relevant symptoms and function remains a hypothesis that is still to be proven. ${ }^{25}$ A recent cross-sectional study of Barker et $\mathrm{al}^{26}$ on patients with severe $\mathrm{OA}$ of the knee found a considerable variety in function, pain, and muscle strength within patients with graphic score. Radiographic and laboratory findings do not correlate well with the disease itself; therefore, the diagnosis is made by clinical findings. Joint pain is the cardinal clinical presentation. ${ }^{27}$ In epidemiologic studies, often, but not always, a radiograph is used for the diagnosis of OA. Radiograph-based studies and those using history and clinical findings roughly come to the same result. On the other hand, some studies have relied on a self-reported diagnosis. This approach correlates poorly with confirmed disease. ${ }^{13}$ For these reasons and because a history/clinical-based diagnosis is of more functional relevance, we chose not to use radiographic evaluation and instead used the clinical ACR criteria.

It is possible that some bias may have arisen because we used the database of prosthetics companies. However, the database of the rehabilitation centers was not accurate enough to trace all traumatic leg amputees. One of the reasons was that some of the older amputees were erased from the rehabilitation database because they had been finished with rehabilitation care for over 10 years. Because of Dutch law, medical records have to be destroyed 10 years after the last visit. In the prosthetic company database, all amputees are invited to have their prosthesis updated at least every 3 years, which makes their database more complete and reliable. To include as many participants as possible, which is necessary considering the low prevalence of OA, we chose to conduct the study on basis of the database of 2 prosthetic companies in 2 cities. This also enlarges the representation and therefore the external validity of the study. In the further course of the study, the 2 companies were not involved in any way. All amputees supervised by the prosthetic companies were initially referred by the rehabilitation centers. Therefore, our study population is representative for the regular rehabilitation population.

\section{CONCLUSIONS}

In comparison to the prevalence of $\mathrm{OA}$ in the general population according to general practitioners' registration, we found a significantly higher prevalence of both knee OA and hip OA of the intact limb in the amputee population. As a result of the study, we believe that the implementation of preventive measures for OA in the rehabilitation management of amputees should be considered.

Acknowledgments: We thank the prosthetic companies LIVIT in Eindhoven and Tilburg for putting their databases at our disposal. We thank F. Struyf, PT, for his technical support in the use of SPSS.

\section{References}

1. Czerniecki JM. Rehabilitation in limb deficiency. 1. Gait and motion analysis. Arch Phys Med Rehab 1996;77(3 Suppl):S3-8.

2. Kulkarni J, Adams J, Thomas E, Silman A. Association between amputation, arthritis and osteopenia in British male war veterans with major lower limb amputations. Clin Rehabil 1998;12:348-53.

3. Norvell DC, Czerniecki JM, Reiber GE. The prevalence of knee pain and symptomatic knee osteoarthritis among veteran traumatic amputees and nonamputees. Arch Phys Med Rehabil 2005;86: 487-93.

4. Sowers M. Epidemiology of risk factors for osteoarthritis: systemic factors. Curr Opin Rheumatol 2001;13:447-51.

5. Jordan JM, Kington RS, Lane NE, et al. Osteoarthritis: new insights. Part 1: the disease and its risk factors. Ann Intern Med 2000;133:635-46.

6. Spector TD, MacGregor AJ. Risk factors for osteoarthritis: genetics. Osteoarthritis Cartilage 2004;(12 Suppl A):S39-44. 
7. Buckwalter JA, Lane LE. Athletics and osteoarthritis. Am J Sports Med 1997;25:873-81

8. Kujala UM, Kettunen J, Paananen H, et al. Knee osteoarthritis in former runners, soccer players, weight lifters, and shooters. Arthritis Rheum 1995;38:539-46.

9. Felson DT, Hannan MT, Naimark A. Occupational physical demands, knee bending and knee osteoarthritis: results from the Framingham Study. J Rheumatol 1991;18:1587-92.

10. Melzer I, Yekutiel M, Sukenik S. Comparative study of osteoarthritis of the contralateral knee joint of male amputees who do and do not play volleyball. J Rheumatol 2001;28:169-72.

11. Guccione AA, Felson DT, Anderson JJ. The effects of specific medical conditions on the functional limitations of elders in the Framingham Study. Am J Public Health 1994;84:351-8.

12. Kraus VB. Pathogenesis and treatment of osteoarthritis. Med Clin North Am 1997;81:85-112.

13. Felson DT, Zhang Y. An update on the epidemiology of knee and hip osteoarthritis with a view to prevention. Arthritis Rheum 1998;41:1343-55.

14. Felson DT, Zhang Y, Anthony JM, Naimark A. Weight loss reduces the risk for symptomatic knee osteoarthritis in women. The Framingham study. Ann Intern Med 1992;116:535-9.

15. Kawasaki T, Inoue K, Ushiyama T, Fukuda S. [Assessment of the American College of Rheumatology criteria for the classification and reporting of osteoarthritis of the knee] [Japanese]. Ryumachi $1998 ; 38: 2-5$

16. Altman R, Alarcón G, Appelrouth D, et al.The American College of Rheumatology criteria for the classification and reporting of osteoarthritis of the hip. Arthritis Rheum 1991;34:505-14.

17. Altman R, Asch E, Bloch D, et al. Development of criteria for the classification and reporting of osteoarthritis. Classification of osteoarthritis of the knee. Diagnostic and Therapeutic Criteria Committee of the American Rheumatism Association. Arthritis Rheum 1986;29:1039-49.
18. Ekstrand MD, Viktorson W, Öberg M. Lower extremity goniometric measurements: a study to determine their reliability. Arch Phys Med Rehab 1982;63:171-5.

19. Rommers GM. Mobiliteitsschalen bij beengeamputeerden: een review. Stimulus 2004;23:456-71.

20. Rommers GM, Vos LD, Groothoff JW. Mobility of people with lower limb amputations: scales and questionnaires: a review. Clin Rehabil 2001;15:92-102.

21. Tzamaloukas AH, Patron A, Malhotra D. Body mass index in amputess. JPEN J Parenter Enteral Nutr 1994;18:355-8.

22. Schouten JS, Gijsen R, Poos MJ. Hoe vaak komt artrose voor en hoeveel mensen sterven eraan? In: Volksgezondheid Toekomst Verkenning, Nationaal Kompas Volksgezondheid. Gezondheid en ziektelZiekten en aandoeningen\Bewegingsstelsel en bindweefsel. Available at: http://www.nationaalkompas.nl. Accessed May 16, 2003.

23. Geertzen JH, Bosmans JC, Van der Schans CP. Claimed walking distance of lower limb amputees. Disabil Rehabil 2005;27:101-4.

24. Stitik TP, Foye PM. The prevalence of knee pain and symptomatic knee osteoarthritis among veteran traumatic amputees and nonamputees. Arch Phys Med Rehabil 2005;86:1273.

25. Lohmander L. What can we do about osteoarthritis? Arthritis Res 2000;2:95-100

26. Barker K, Lamb SE, Toye F, Jackson S, Barrington S. Association between radiographic joint space narrowing, function, pain and muscle power in severe osteoarthritis of the knee. Clin Rehabil 2004;18:793-800.

27. Sinkov V, Cymet T. Osteoarthritis: understanding the pathophysiology, genetics, treatments. J Natl Med Assoc 2003;95:475-82.

\section{Supplier}

a. Mediclino, Kuntoväline oy, Oltermannintie 8, 00620 Helsinki, Finland.

b. SPSS Inc, $233 \mathrm{~S}$ Wacker Dr, 11th Fl, Chicago, IL 60606. 